\title{
INCLUSÃO DA MOBILIDADE SUSTENTÁVEL NA REESTRUTURAÇÃO DA CIDADE DE SÃO BERNARDO DO CAMPO
}

\author{
Patrícia Helen Lima, Arquiteto Urbanista* \\ * Mestre em Projeto Sustentável pela FAUUSP, \\ Doutoranda em Infraestrutura Verde pela FAUUSP \\ Coordenadora da Seção de Informação da Qualidade Ambiental da PMSBC \\ E-mail: patricia.helen.lima@usp.br
}

\begin{abstract}
RESUMO
Este artigo trata da relação do espaço público da cidade com o poder econômico, político e social, e de como a mobilidade e a infraestrutura verde podem, muito além de interconectar áreas do território, propor novas espacialidades que traga significado aos novos projetos que estão sendo criados nas metrópoles atuais, transformando a sociedade e a forma urbana.

São apresentadas inúmeras intervenções no município de São Bernardo do Campo, que possibilitam construir novos espaços, melhorar os já existentes, propondo valores objetivos, subjetivos e coletivos, abrindo espaço para uma reestruturação da cidade. Palavras-chave: Espaço público, Mobilidade, Infraestrutura verde, Forma urbana, Valores coletivos.
\end{abstract}

\section{SUSTAINABLE MOBILITY INCLUSION IN THE RESTRUCTURATION OF THE CITY OF SÃO BERNARDO DO CAMPO}

\begin{abstract}
ABTRACT
This article deals with the relation of the public space of the city with the economic, political and social authorities, and how the mobility and green infrastructure can, besides interconnect areas the territory, propose new environments that bring significance to new projects being created in cities today, transforming the society and the urban form.
\end{abstract}

Several interventions in the city of São Bernardo do Campo are presented, enabling to 
build new spaces, improve existing ones, and propose objective, individual and collective values, making room for a restructuration of the city.

Key words: Public Space, Mobility, Green Infrastructure, Urban Form, Collective Values.

\section{INTRODUÇÃO}

A cidade é um assunto que engloba tudo, desenvolvimento econômico, cultura, recursos ambientais, justiça social, memória, locomoção, comunidades, mas traça caminhos independentes sem ser pensada como parte de um sistema global único, partilhando elementos de referência urbana comuns.

Somos testemunhas de visões urbanas utópicas ou sistemas políticos que permitiram caminhos da ostentação do crescimento. Cidades demolidas e reconstruídas, devastadas em sua natureza, indefinido em seus espaços públicos. Este é o ponto mais crítico do limite que alcançamos nas cidades e metrópoles neste início de século em que vivemos.

Uma cidade precisa ser clara acerca do seu espaço privado e público e de seus padrões de movimentação. $O$ espaço público exige a possibilidade do movimento e este significa acesso, que significa pensar o espaço simbólico, natural e técnico, o espaço que percebemos e que nos apropriamos associado aos custos e as obrigações de fazermos parte dele. Isso é mobilidade.

O problema da mobilidade urbana é visto apenas como um problema de trânsito, sendo necessário superar outros gargalos do modelo de transporte relacionado a outros aspectos da vida urbana, como acesso ao emprego, ao estudo e ao lazer.

"O fenômeno da mobilidade envolve uma série de fatores e processos distintos que estão, ao mesmo tempo, na base estrutural do sistema produtivo e no cotidiano vivido das pessoas, englobando todo o sistema de transportes e a gestão pública desses espaços, passando pela forma urbana, as interações espaciais até as dinâmicas demográficas específicas (estrutura familiar, migração, ciclo vital). Urge um olhar mais amplo sobre a mobilidade, que não a associe de forma direta e rasteira ao deslocamento físico, mas que Ihe conceda os atributos de um fenômeno propriamente dito (MARANDOLA, 2008)". 
Neste contexto, é preciso reconhecer a fragmentação criada nas cidades e buscar possibilidade de conexões, que nos coloque frente aos desafios da infraestrutura de transporte e infraestrutura verde que possibilitem a mobilidade em sua integridade.

\section{A FORMA DA CIDADE}

A violência urbana induz à recusa da convivência e os muros reforçam a condição de segregação. São criados parques urbanos desconectados, espaços e vias públicas muitas vezes fechadas ao acesso de pessoas. As cidades com seus investimentos imobiliários em qualquer localização infraestruturada afastam populações menos privilegiadas e obrigam o espalhamento urbano desenfreado e irresponsável.

As cidades precisam ser mais inclusivas, pensadas em suas especificidades buscando conectar seu tecido social com a intenção de alcançar um equilíbrio no espaço, cuidar de suas riquezas naturais e promover condições prazerosas e eficientes de mobilidade.

A qualidade do domínio público é importante e nos conduzem ao orgulho e satisfação de onde moramos, nos leva à percepção dos espaços, da qualidade de onde estamos, o sentido de inclusão. Esta nova abordagem da percepção dos espaços públicos, ambiental e da qualidade da mobilidade agem como canais de integração.

\section{MOBILIDADE URBANA}

O conceito de mobilidade, conforme indicado na Lei de Diretrizes da Política Nacional de Mobilidade Urbana $n^{\circ} 12.587 / 2012$, refere-se à condição em que se realizam os deslocamentos de pessoas e cargas no espaço urbano, e pode ser entendido como a facilidade de deslocamento. Por vezes é vinculada àqueles que são transportados ou se transportam e, por outras, relacionado à cidade ou ao local onde o deslocamento pode acontecer.

Neste trabalho, focamos com maior ênfase artigos da Lei que remetem a cidade e o local onde os deslocamentos podem acontecer. Dentre as principais medidas propostas, para seguir o raciocínio da importância do espaço público para a conexão urbana e, portanto, para os deslocamentos, destacamos o Desenvolvimento sustentável das cida- 
des e Equidade no uso do espaço público de circulação (Art. $n^{\circ}$ 5), Integração com as políticas de uso do solo e desenvolvimento urbano (habitação, saneamento); Mitigação dos custos ambientais dos deslocamentos de pessoas e cargas na cidade (Art. $\mathrm{n}^{\circ} 6$ ).

A lei estabelece diretriz e instrumentos para que os municípios possam executar uma política de mobilidade urbana que promova o acesso universal à cidade e contribua para o desenvolvimento urbano sustentável, no entanto, a questão da Equidade no uso do espaço público nos remete às questões da apropriação seletiva e diferenciada de espaços, citado anteriormente, induzindo à segregação que hoje encontramos nas cidades e o papel do Estado e do Mercado na conformação deste espaço público urbano. Serpa (2004) evidencia, ainda, a dificuldade de relacionar as dimensões políticas e sociais de uma esfera pública urbana e os aspectos formais e estruturais dos espaços públicos "concretos", para alertar de que forma intervir para que a cidade seja acessível a todos. Esta diretriz deve embasar a produção do espaço, no planejamento urbano, arquitetônico, ambiental e paisagístico.

A preocupação com a sustentabilidade está relacionada com as diferentes atividades que são desenvolvidas na cidade e que resultam em determinadas pressões e impactos ambientais. As atividades têm diferentes impactos em função da sua localização e tipologia, sendo necessário analisar as políticas do uso do solo que permitam equilíbrio do desenvolvimento socioeconômico e atividades. A mobilidade em seu objetivo deve interligar todas as atividades definidas pelo uso do solo. Desta forma, se estabelece uma inter-relação entre Desenvolvimento, Políticas de Transporte e Uso do Solo.

As pressões e impactos ambientais remetem ao debate ecológico estabelecido desde o final do século XX, começando a ser entendido como condição necessária do pensamento urbano, onde a expansão da cidade deve ser repensada e as conexões devem ser preponderantes nos diversos níveis: social, espacial, cultural, político etc.

A nova Lei, portanto, reconhece a existência de desigualdades no uso do espaço público, fornece segurança jurídica para que os municípios possam tomar medidas de priorização de usos coletivos, e abre a possibilidade para que ações e investimentos das prefeituras que venham a contrariar as diretrizes fixadas na lei possam ser contestados pela sociedade, porém, Ela não é suficiente para garantir sustentabilidade das cidades, sendo necessário que o Poder Público Municipal faça as devidas adequações e implementações às diretrizes e instrumentos da lei à realidade de suas cidades (IPEA - Instituto de Pesquisa Econômica Aplicada, 2012). 


\section{INFRAESTRUTURA VERDE}

Adequação à realidade das cidades requer detalhado conhecimento do padrão de distribuição de usos no território e a compreensão sobre a complexidade dos elementos que compõe o meio. A infraestrutura verde, utilizando uma metodologia sistêmica de Planejamento e Gestão Ambiental, subsidiada pela cartografia e sistemas de informações geográficas possibilita uma visão crítica do espaço fragmentado das cidades ${ }^{1}$.

BENEDDICT, MCMAHON, 2006 definem infraestrutura verde como uma rede interconectada de áreas naturais e outros espaços abertos que conservam valores e funções de ecossistemas naturais, diferindo da abordagem de conservação e proteção convencional por considerar desenvolvimento e planejamento ambiental como parte do mesmo sistema. Orienta a criação de um sistema de áreas, de espaços abertos, espaços verdes conectados e que associados aos espaços recreativos dão suporte a conservação ambiental entrelaçado aos usos de forma adequada da terra.

A criação de um sistema de áreas, baseado no uso da terra, condicionantes físicas e identificação social possibilitarão a definição de Unidades de configuração homogênea que apresentem suas vocações para proteção, recuperação ambiental ou conservação, em conjunto com a caracterização dos espaços livres definirão as conexões naturais e urbanas possíveis. A mobilidade urbana se conforma por tais análises.

Este modelo que gerencia, com base no diagnóstico urbano, as intervenções no ambiente coloca em foco as conexões ambientais e a mobilidade como espinha dorsal.

Sabemos que solução de mobilidade com base no automóvel é dominante de forma desproporcional, porém investimentos em transporte público com novas tecnologias e legislações para mobilidade urbana apontam para as políticas de sustentabilidade e com esforços para aproximar estratégia de padrões de uso da terra e padrões de mobilidade, ou seja, a criação de malhas de transporte público, integradas e operacionais, que se estenda por uma ampla área urbana e ambiental, deverá trazer um novo modelo de mobilidade sustentável.

1 O Planejamento e Gestão ambiental objetivam compatibilizar o crescimento físico-territorial com seus usos, segundo suas características ambientais e a representação cartográfica tem fundamental importância. O mapeamento identifica e delimita padrões de distribuição e a relação entre os componentes distribuídos no espaço, favorecendo a síntese da informação e a sistematização dos elementos (SANTOS, 2004). 


\section{IMAGEM DA CIDADE}

"A cidade é uma construção no espaço, mas uma construção em grande escala."

Kevin Lynch, 1997

Um ambiente urbano raramente é percebido em sua totalidade pelos seus habitantes, que praticamente não tem consciência do valor potencial de entornos harmoniosos, daquilo que um determinado espaço pode significar em termos de prazer cotidiano. É preciso levar em consideração não apenas a cidade em si, mas a cidade do modo como é percebida por seus habitantes (LYNCH, 1997).

A apropriação do local por seus moradores traz em si respeito e orgulho. O sentido de coletividade se manifesta e o comprometimento e as ações para a melhoria ambiental e de vida patrocinam a identidade daquele lugar, novos hábitos, novos valores, que repercutem junto à sociedade como um todo.

Um novo objeto pode dar a impressão de uma identidade sólida e positiva devido a características físicas notáveis que sugerem e até mesmo pode impor seu próprio padrão de beleza e qualidade em um ambiente que venha a ser usado por muitas pessoas.

As imagens públicas comuns a vastos contingentes de habitantes de uma cidade podem criar áreas consensuais que pode se esperar que surja uma cultura comum e de uma natureza básica.

"O mundo pode ser organizado em torno de um conjunto de pontos focais, ou fragmentado em regiões designadas por nomes, ou ainda, interligado por caminhos passíveis de serem lembrados. Variados como são esses métodos, e inesgotáveis como parecem ser os indicadores potenciais que um homem pode selecionar para diferenciar seu mundo, eles proporcionam interessantes informações subsidiárias sobre os meios que hoje usamos para nos localizarmos em nosso mundo urbano. (LYNCH, 1997)."

Segundo LYNCH (1997), uma imagem é composta de identidade (individualidade), estrutura (relação espacial) e significado (emocional para o observador). Uma vez que este é um processo interativo entre o observador e o que se observa é possível refor- 
çar a imagem através de artifícios simbólicos. Da mesma forma, somos capazes de apreender as formas da natureza nas cidades, com a nossa percepção do ambiente. É no sistema de relações com o que lhe é externo, ou seja, com a alteridade, que a territorialidade pode ser definida. Ela está impregnada de laços de identidade, que tentam de alguma forma homogeneizar esse território, dotá-lo de uma área/superfície minimamente igualizante, seja por uma identidade territorial, seja por uma fronteira definidora de alteridade (Serpa, 2004).

A proposta de conexões ambientais e da mobilidade como espinha dorsal pode, neste momento de grandes mudanças, criar valores estabelecidos na melhoria de sua forma urbana e no padrão de seus projetos estruturais. Estamos diante da oportunidade de adequação aos novos parâmetros ambientais consensuados democraticamente e da oportunidade de definir um conjunto de princípios e regras orientadoras para os agentes que constroem e utilizam o espaço urbano.

A sociedade começa a mudar a percepção de seu papel passivo diante dos impactos na natureza, sejam pelas alterações climáticas, vulnerabilidades físicas. Os espaços antrópicos decorrentes dos impactos das atividades humanas já trouxeram severos danos aos sistemas naturais e que geram muitas vezes efeitos imprevisíveis. A capacidade de o sistema natural absorver perturbações e reorganizar-se, ou seja, a resiliência de suportar perturbações e se auto-organizar poderá definir parâmetros para construir valores e relacionamentos que possibilitem atingir objetivos de desenvolvimento que determinem um futuro melhor.

De acordo com (Berkes and Folke 1998; Barnett 2001) citados no relatório Urban Resilience. Research Prospectus (CSIRO, 2007), diferente do que geralmente se pensa, a resiliência urbana não está tanto no contexto de resposta a um impacto, mas sim numa lógica de sistema com a sua capacidade de mudança e adaptação contínua, considerando os seus fluxos, as suas dinâmicas sociais, as redes de governança, o ambiente biofísico, etc. As mudanças bruscas nas cidades dependem de perspectivas espaciais e temporais.

\section{POLÍTICAS DE TRANSPORTE}

A presidente Dilma Rousseff anunciou em 24/04/12 os projetos selecionados pelo Programa de Aceleração do Crescimento (PAC) para a área de mobilidade urbana nas 
grandes cidades. Ela defendeu a necessidade de ampliar os investimentos na construção de metrôs para dar mais agilidade e conforto aos usuários do transporte urbano.

O Município de São Bernardo do Campo encontra-se entre estas cidades e tem o Estudo de Impacto Ambiental - EIA e seu correspondente Relatório de Impacto Ambiental - RIMA, relativos à "Implantação da Linha 18 - Bronze - Trecho Tamanduateí -Alvarenga",em análise pela CETESB/SMA.

O Município possui uma população de 746.718 habitantes, segundo Censo IBGE 2010, e um território com $407 \mathrm{~km} 2$. Cerca de $50 \%$ ou $210 \mathrm{~km}^{2}$ do Município estão inseridos na Área de Proteção e Recuperação dos Mananciais do Reservatório Billings (APRM - B), maior reservatório de água da Região Metropolitana, com cerca de $76 \mathrm{~km}^{2}$ ocupados só pelo espelho d'água do reservatório, quase $19 \%$ da área total do município, e outros $6 \mathrm{~km}^{2}$ referentes ao espelho d'água do Reservatório Rio das Pedras. Comporta importante reserva ambiental referente ao Parque Estadual da Serra do Mar², integrando a Reserva da Biosfera do Cinturão Verde da Cidade de São Paulo.

Além da forte caracterização ambiental e da apresentação do EIA-RIMA à CETESM/ SMA, estão em processo programas de intervenção territorial, com ênfase no Plano Local de Habitação de Interesse Social - PLHIS e em paralelo teve no ultimo ano a revisão do Plano Diretor, adequando-se aos novos parâmetros da Lei específica da Billings. Outro grande desafio é o empreendimento Rodoanel Mário Covas - Trecho Sul, inaugurado em $1^{\circ}$ de abril de 2010 . Trata-se de um empreendimento entre impactos positivos e negativos, pois dados o vulto da obra rodoviária e a fragilidade das regiões por onde se projetou seu traçado, são previsíveis impactos significativos sobre os já escassos remanescentes de Mata Atlântica existentes na Região Metropolitana de São Paulo.

A implantação da Linha do metrô apresenta-se em meio ao desenvolvimento desses trabalhos em curso que, seguidamente, se confrontam com temáticas fragmentadas e não interligadas e justificam a necessidade da adequabilidade de todas as intervenções, onde a infraestrutura verde apresenta-se como suporte para tantas propostas sobre a cidade.

2 A área do Parque Estadual no município é de aproximadamente $135 \mathrm{~km}^{2}$ ou 13.544 hectares. Recentemente houve inclusão de áreas no Parque, o que no município corresponde a um aumento de 1791 hectares de área protegida (PMSBC). 
Este empreendimento consolidará uma ligação metropolitana de média capacidade, articulando o Município de São Bernardo do Campo e região do $A B C$ com a Rede Metroferroviária da RMSP, no Município de São Paulo, utilizando como ponto de integração a Estação Tamanduateí da Linha 2 - Verde do Metrô e a Linha 10 - Turquesa da Companhia Paulista de trens Metropolitanos - CPTM.

A extensão total dessa linha proposta somará aproximadamente $20 \mathrm{~km}$, estando nela projetadas 18 estações, cujo traçado do eixo principal se iniciará na região de Alvarenga, na porção sudoeste do Município de São Bernardo do Campo, passando pela região central e Paço Municipal, seguindo pelo eixo da Av. Lauro Gomes, na divisa com os municípios de Santo André e São Caetano do Sul, e pelo eixo da Av. Guido Aliberti, divisa entre os municípios de São Paulo e São Caetano do Sul, até atingir a região das Estações Tamanduateí da CPTM e do Metrô, na Cidade de São Paulo (Fig.1).

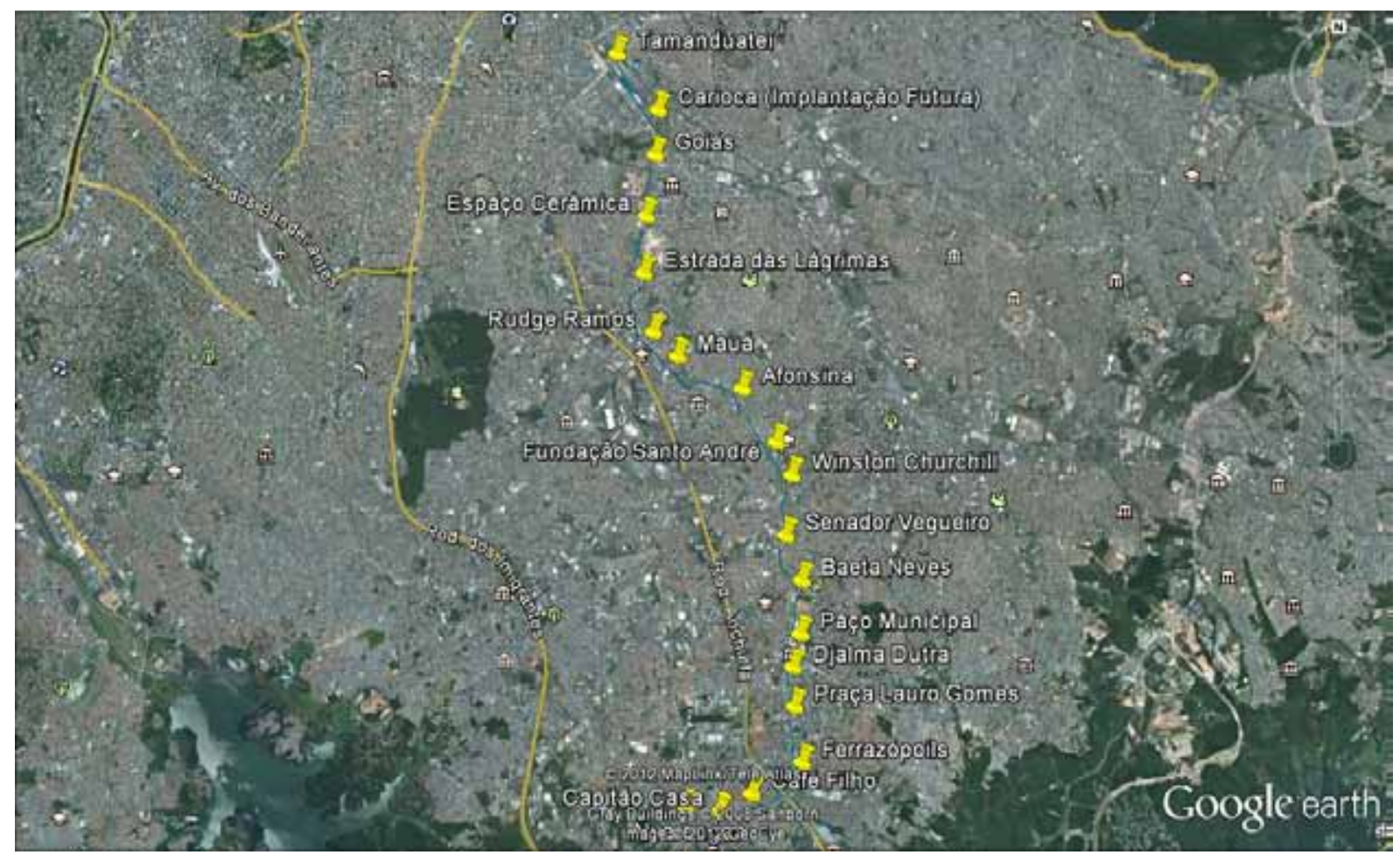

Figura 1: Apresentação da região de inserção do Trecho Tamanduateí -Alvarenga, da Linha 18 - Bronze. Fonte: Metrô. Gestão ambiental.

Esta ligação está prevista para operar com praticamente a totalidade do traçado em elevado e o trecho nas proximidades da Estação Tamanduateí em nível, partilhando a faixa de domínio ferroviária, contando, ainda, com a tecnologia Monotrilho e as estações elevadas (Fig.2). 

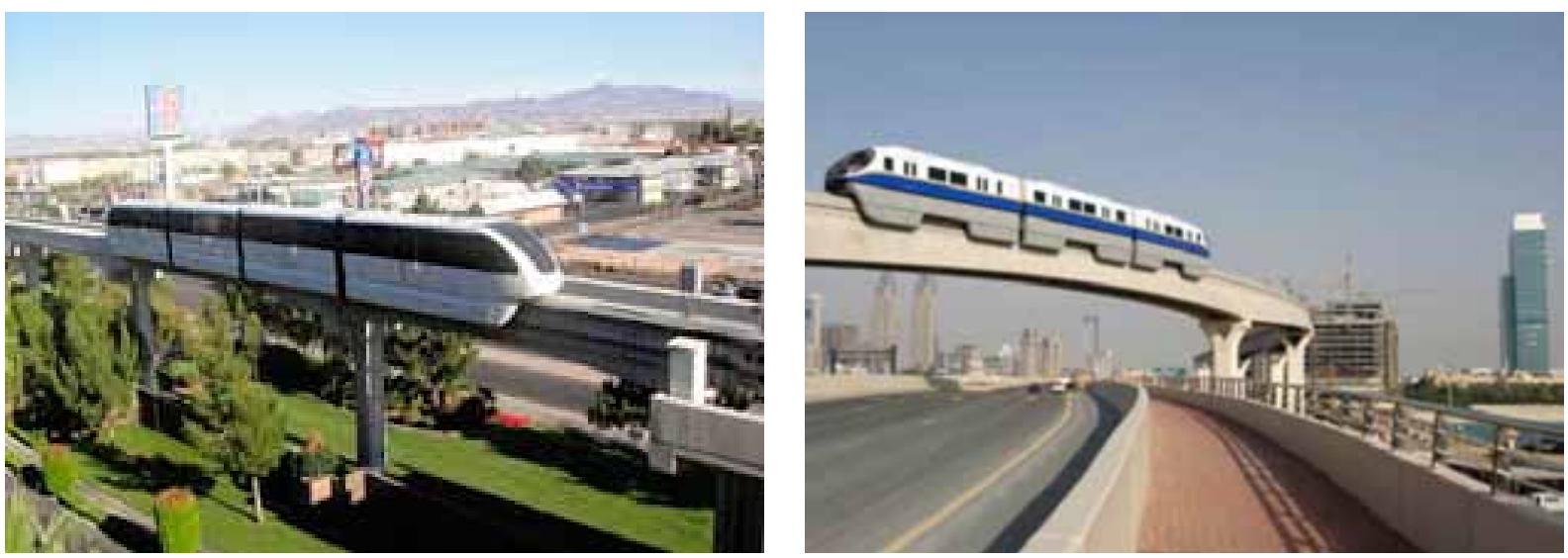

Figuras 2 e 3: Proposta de Monotrilho elevado. Fonte: Metrô. Gestão ambiental

\section{MOBILIDADE}

Como objetivo geral, a Linha 18 - Bronze visa proporcionar, para a população residente na região metropolitana, um transporte público seguro, rápido, acessível e ambientalmente sustentado.

Da mesma forma, irá preencher uma lacuna, em termos de integração metropolitana, através da Rede Metro ferroviária, permitindo ainda que os municípios de Santo André, São Caetano do Sul e mesmo São Paulo possam adotar novas estratégias de articulação metropolitana através de vias e suas regiões de entorno, atualmente com pouco uso pelo transporte coletivo, como é o caso das avenidas Lauro Gomes e Guido Aliberti, ambas na diretriz viária estabelecida para o traçado do novo sistema de transporte.

Objetivos da implementação da linha 18:

I - garantir e melhorar a circulação e o transporte urbano proporcionando deslocamentos intra e interurbanos que atendam às necessidades da população;

II - priorizar o transporte coletivo ao transporte individual;

III - tornar mais homogênea a acessibilidade em toda a área urbanizada da Cidade;

IV - aumentar a acessibilidade e mobilidade da população de baixa renda;

$V$ - proporcionar maior segurança e conforto aos deslocamentos de pessoas e bens, com redução dos tempos e custos;

VI - reduzir a ocorrência de acidentes e mortes no trânsito;

VII - tornar o sistema de transporte coletivo um provedor eficaz e democrático de mobilidade e acessibilidade urbana; 
IX - ampliar e melhorar as condições de circulação de pedestres e de grupos específicos, como idosos, portadores de deficiência especial e crianças;

$X$ - garantir a universalidade do transporte público;

XII - reduzir a carga poluidora gerada pelo sistema de transportes, incluindo a implantação gradativa de ônibus movidos a fonte de energia limpa, de modo a respeitar os índices de qualidade ambiental definidos pela legislação do órgão técnico competente; (Metrô. EIA-RIMA - Estudo de Impacto Ambiental e Relatório de Impacto Ambiental LINHA 18 - BRONZE - Trecho Tamanduateí / Alvarenga).

A proposta da Linha 18 - Bronze busca aprimorar o sistema de transporte, mas é preciso pensar na transformação da paisagem onde as infra-estruturas (da mobilidade) serão construídas, que além de contribuir para o crescimento do espaço urbanizado, transforma os modos de deslocamentos, modifica a relação com o espaço, impõem novo ritmo urbano e onde o natural e o artificial devem se entrelaçar para que haja um desenvolvimento pouco predador no território, capaz de adequar estas novas práticas do espaço.

As superposições de novas intervenções no território demandam identificar interferências de tantos projetos e combinações na direção da construção de novas adequações cidade-paisagem, novos princípios de organização e novos tipos de espaços públicos, para que seja possível a leitura deste novo cenário pelos habitantes.

\section{Avalização dos impactos ambientais}

A identificação e a avaliação dos impactos serão realizadas relacionando-se as ações do empreendimento, nas suas distintas fases, consideradas como geradoras de interferências em uma dada área de influência, nos aspectos ambientais diagnosticados, cada um com maior ou menor grau de vulnerabilidade.

Conhecido o processo potencial de mudança na qualidade ambiental preexistente, os impactos serão avaliados segundo um conjunto de atributos, sendo que todo este conjunto de atributos permitirá classificar a magnitude dos impactos. Na avaliação dos impactos ainda será possível a mensuração de alguns deles, por meio de indicadores.

Por sua vez, na avaliação final dos impactos serão destacados aqueles de maior importância no contexto das áreas de influência do empreendimento projetado, subsidiando 
as conclusões sobre as condições pelas quais se poderá garantir a viabilidade ambiental da implantação da Linha 18 - Bronze - Trecho Tamanduateí/Alvarenga (Fig.4).
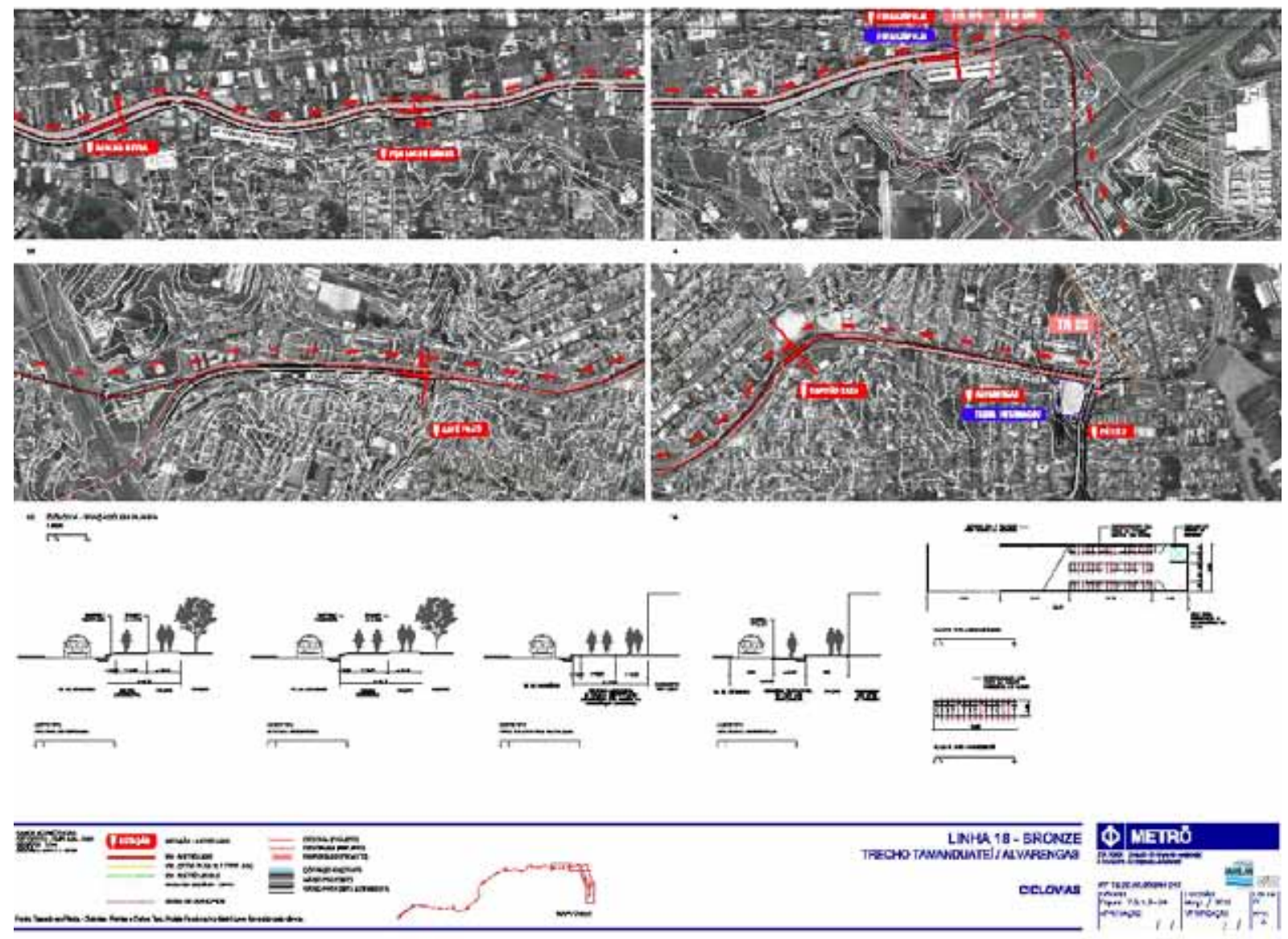

Figura 4: Apresentação da ciclovia que será implantada em todo o trajeto da linha. Fonte: Metrô. Gestão ambiental

\section{CONSIDERAÇÕES FINAIS}

A abordagem da questão urbana é complexa e exige observar os efeitos das intervenções na cidade e implica na avaliação de grande volume de informações. Diante dos inúmeros projetos em andamento e recém-aplicados em São Bernardo do Campo, com a nova proposta de mobilidade sustentável torna-se imperativo a construção de novas bases com mudanças profundas no modo de vida de cada um dos atores da cidade, e exige um questionamento intenso das representações e das praticas urbanas habituais.

Este momento marca um exemplo de reestruturação da cidade e cria uma nova urbanidade metropolitana que deve ser considerada. Na base dessas transformações estão importantes reformulações em diversos campos que confrontam com novos valores. A condição urbana resultante exige novos tipos de organização espacial cujos 
princípios ordenadores são muito diferentes dos anteriores. Essa nova condição deverá ser nutrida pela qualidade dos novos espaços que serão criados e a percepção que os habitantes têm destes espaços públicos volta a ter grande relevância.

Ao poder público cabe criar os mecanismos de reformulação territorial para atender a esfera urbana contemporânea, possibilitando novas relações entre áreas públicas e a transposição da cidade, que deverão ser organizadas através da alta qualidade urbanística, paisagística e arquitetônica.

A cidade tem uma capacidade de suporte que deve ser entendida, respeitada e promovida com qualidade que o projeto deve possibilitar, respeitando o sistema da resiliência urbana, assim como a resiliência específica de cada tema, com habilidade para que a sociedade possa absorver, se adaptar e se reorganizar.

\section{BIBLIOGRAFIA}

BENEDICT, Mark A., MCMAHON, Edward T. Green infrastrustructure: linking landscapes and communits. Washington, DC: ISLAND PRESS, 2006.

CSIRO (2007), Urban Resilience. Research Prospectus. A Resilience Alliance Initiative for Transitioning Urban Systems towards Sustainable Futures. CSIRO, Australia — Arizona State University, USA — Stockholm University, Sweden, fevereiro, 2007.

http://www.ipea.gov.br

http://www.metro.sp.gov.br

http://www.urban-age.net

LINCH, Kevin. A imagem da cidade. São Paulo:Martins Fontes, 1997.

MARANDOLA Jr.,Eduardo. Novos significados da mobilidade. Revista Brasileira de Estudos de População, São Paulo, v. 25, n. 1, p. 199-200, jan./jun. 2008. Disponível em http://www.scielo.br/pdf/rbepop/v25n1/v25n1a13.pdf. Acesso em 18 out.

SANTOS, Rozely Ferreira dos. Planejamento Ambiental: teoria e prática. São Paulo: Oficina de Textos, 2004.

SERPA, Angelo. Espaço público e acessibilidade: notas para uma abordagem geográfica. GEOUSP - Espaço e Tempo, São Paulo, n¹5, 2004. 